\title{
Denudation and sperm injection interval timing: impact on outcome of intracytoplasmic sperm injection
}

This article was published in the following Dove Press journal:

International Journal of Women's Health

16 March 2011

Number of times this article has been viewed

Background: Given the importance of timing of denudation and oocyte injection during assisted reproductive technology cycles, a study was undertaken of the impact of timing on the outcome of intracytoplasmic sperm injection in a cohort of patients from a private in vitro fertilization center.

Methods: The study included patients who underwent fresh intracytoplasmic sperm injectionembryo transfer by a single embryologist and gynecologist over a two-year period (January 2008 to March 2010). The primary outcome measure was the number of mature oocytes, and clinical pregnancy was the secondary outcome measure.

Results: There was no significant difference between the three groups with respect to female age, but Group 3 showed a higher mean number of cumulus oopherus (14.46 versus 14.19), mature oocytes at time of denudation (12.72 versus 11.71), metaphase II injected (13.04 versus 11.85 ), and fertilized oocytes ( 9.75 versus 8.25) than Group 2. Group 2 showed a higher number of cumulus oopherus (14.19 versus 13.11), mature oocytes at time of denudation (11.71 versus 9.37), metaphase II injected (11.85 versus 9.7), and fertilized oocytes ( 8.25 versus 6.86 ) than Group 1 . The maturation index, as well as positive clinical pregnancies, was significantly higher in Group 2 than Group 1 and in Group 3 compared with Group 1. Comparing Group 2 and Group 3, there was no significant difference regarding clinical pregnancy rates.

Conclusion: It is preferable to allow an interval between oocyte retrieval and sperm injection.

Keywords: denudation, oocyte, intracytoplasmic sperm injection, pregnancy

\section{Introduction}

Approximately $20 \%$ of oocytes routinely retrieved following hormone stimulation are classified as immature (termed germinal vesicle, or metaphase I stage). These oocytes are discarded due to their reduced potential for embryo development under current culture conditions. ${ }^{1}$ The cumulus cells that surround oocytes within follicles modulate nuclear and cytoplasmic maturation by both physical cell-cell contact and the combined actions of paracrine factors. ${ }^{2}$ However, during the process of intracytoplasmic sperm injection, cumulus cells must be removed from oocytes, which normally would mature the oocytes. ${ }^{3}$

A prolonged interval between human chorionic gonadotrophin administration and

Correspondence: F Aletebi Gynaecology, King Abdulaziz University, Soliman Fakeeh Hospital, Jeddah, Saudi Arabia

Tel +966503002383

Fax+966 64010002966

Email faletebi@yahoo.com oocyte retrieval in conventional controlled ovarian hyperstimulation cycles increases the production of oocytes and embryo developmental competence. ${ }^{4,5}$

The cumulus cells were deemed to be expanded when they had cells detached from the oocyte with matrix visible between cumulus cells. ${ }^{6,7}$ In 2009 , Vanhoutte et al 
concluded that during conventional in vitro maturation, oocytes undergo nuclear maturation, but do not attain full cytoplasmic maturity, while the in vitro maturation of oocytes in the presence of granulosa cells in the culture system promoting cytoplasmic maturation was assessed by the oocytes' capability to fertilize after intracytoplasmic sperm injection and sustain further embryonic development.

\section{Materials and methods}

The present study was conducted at the In Vitro Fertilization Unit at Soliman Fakih Hospital, Saudi Arabia. Three hundred and nine intracytoplasmic sperm injection-embryo transfers were performed by a single provider and a single embryologist over a two-year period of time. Patients were divided into three groups, ie, Group 1 (oocyte denudation and injection done immediately after ovum pickup in intracytoplasmic sperm injection-embryo transfer cycles), Group 2 (oocyte denudation and injection, each done within one hour of ovum pickup in intracytoplasmic sperm injection-embryo transfer cycles) and Group 3 (oocyte denudation and injection, each done within two hours of ovum pickup in intracytoplasmic sperm injection-embryo transfer cycles).

Participants were selected from those attending the infertility clinic, and each woman was subjected to the following hormonal profile (follicle-stimulating hormone, luteinizing hormone, prolactin, and estradiol) and ultrasound examination. The women were aged up to 39 years, and had normal baseline follicle-stimulating hormone levels, body mass index $\leq 30$, with no uterine abnormalities. Women with partners having sufficient numbers of spermatozoa for oocyte injection, bilateral undescended testes, or Klinefelter's syndrome were excluded from the study. All patients had undergone controlled ovarian stimulation by the antagonist protocol. The dose of gonadotropins was individualized, based on the patient's age, history, and response to medication. Cycles were monitored using serial transvaginal ultrasound to assess follicular growth.

\section{Oocyte collection}

Oocyte maturation was induced by the administration of 10,000 IU of human chorionic gonadotrophin (Pregny ${ }^{\circledR}, \mathrm{NV}$ Organon) when at least three follicles $\geq 17 \mathrm{~mm}$ diameter were present on ultrasound scan. Retrieval of oocytes was done approximately 36 hours after human chorionic gonadotrophin administration, and was performed under transvaginal ultrasound guidance. The aspirates were collected in tubes with prewarmed Earle's Balanced Salt Solution. Collection started with the largest follicle, and oocyte maturity was assessed. Subsequent collection of oocytes without follicle size measurement was performed according to accessibility of the follicles, after which the maturity level of the oocyte was identified under a stereomicroscope.

For Group 2 and Group 3, the oocytes collected were placed in a central well dish with $1 \mathrm{~mL}$ GIVF media and placed in the incubator, but immediate dissection was done in Group 1 under the dissecting microscope with high magnification. The cumulus masses were removed with hyaluronidase and mechanical pipetting, and assessment of maturity was undertaken. The nuclear status of denuded oocytes was subsequently recorded. Germinal vesicle oocytes were not considered for intracytoplasmic sperm injection. Metaphase I oocytes were defined as those in which no germinal vesicle and no first polar body were visible. Metaphase I oocytes were left to mature until the time when intracytoplasmic sperm injection was carried out. Mature oocytes in metaphase II were injected on the same day. Intracytoplasmic sperm injection was performed according to the method described by Van Steirtegham et $\mathrm{al}^{8}$ and Al-Hasani et al. ${ }^{9}$ Matured oocytes were injected by intracytoplasmic sperm injection using the partner's spermatozoa. Intracytoplasmic sperm injection was performed in Group 2 and Group 3 after one hour ${ }^{10}$ and two hours, respectively, but immediate injection was done in Group 1.

\section{Embryo development and transfer}

Injected oocytes were cultured in G1 media, and fertilization was assessed 16-20 hours after injection for the appearance of two distinct pronuclei and two polar bodies. Embryonic development was assessed on day 2 (44-48 hours) and on day 3 (67-72 hours) after intracytoplasmic sperm injection according to the number of blastomeres, fragmentation rate, cell size, symmetry, granulation, vacuolization, and multinucleation, and all dysmorphic characteristics of the embryos were noted. The best quality embryos were transferred on days 2 or 3 after intracytoplasmic sperm injection according to the method described by Schoolcraft et al. ${ }^{11}$ All embryo transfers were performed with a full bladder under ultrasound guidance using the Labotect catheter (Labotect, Göttingen, Germany) and the Hamilton syringe (Reno, NV) by the same gynecologist and single embryologist.

\section{Follow-up}

Pregnancy was diagnosed by the detection of positive serum human chorionic gonadotrophin 14 days after 
embryo transfer, followed by a rise in human chorionic gonadotrophin levels. All patients underwent a transvaginal ultrasound scan at 6-7 weeks of pregnancy to differentiate between biochemical and clinical (presence of an intrauterine gestational sac with fetal heart beat) pregnancies and to diagnose ectopic implantations.

\section{Statistical analysis}

The statistical analysis was done with the SPSS program for Microsoft Windows (Chicago, IL) using the Student's $t$-test or Fisher's Exact test as appropriate. The primary outcome analyzed was the number of mature oocytes, and the secondary outcome was clinical pregnancy rate per transfer, as defined by the presence of a gestational sac on ultrasound at 6-8 weeks of gestation. Cases with no rising human chorionic gonadotrophin titer were not scored as clinical pregnancies.

\section{Results}

The average (standard deviation) age of the patients was $29 \pm 4$ years. The overall pregnancy rate was $41.1 \%$. Group 1 included 132 intracytoplasmic sperm injectionembryo transfers in which oocyte denudation followed ovum pickup immediately and was followed by oocyte injection immediately as well. Group 2 included 72 intracytoplasmic sperm injection-embryo transfers in which oocyte denudation was followed by ovum pickup with approximately one hour in vitro culture, and followed later by oocyte injection within one hour in vitro culture. Group 3 included 105 intracytoplasmic sperm injection-embryo transfers in which oocyte denudation followed ovum pickup, with approximately two hours of in vitro culture, and followed later by oocyte injection within two hours of in vitro culture.

As shown in Table 1, there was no significant difference between groups 1,2 , and 3 for age $(28.75,28.78$, and 29.63 years, respectively), but Group 3 showed a higher mean number of cumulus oopherus (14.46 versus 14.19), mature oocytes at time of denudation (12.72 versus 11.71), metaphase II injected (13.04 versus 11.85), and fertilized oocytes (9.75 versus 8.25$)$ than Group 2. Group 2 showed a higher number of cumulus oopherus (14.19 versus 13.11), mature oocytes at time of denudation (11.71 versus 9.37), metaphase II injected (11.85 versus 9.7), and fertilized oocytes (8.25 versus 6.86) than Group 1.

The maturation index, as well as positive clinical pregnancy, was significantly higher in Group 2 than in Group 1, and in Group 3 compared with Group 1, but there was no significant difference between Group 2 and Group 3 for clinical pregnancy rates (Table 2).

\section{Discussion}

In our study, Group 3 showed a significantly higher maturation index than Group $2(P=0.000)$, and Group 2 showed a higher maturation index than Group $1(P=0.000)$. This is in agreement with a previous report, ${ }^{12}$ describing a significantly higher number of oocytes with fully expanded cumulus cells after delayed oocyte retrieval (39 hours) in patients with polycystic ovary syndrome and controlled ovarian hyperstimulation cycles. Weon-Young et al, ${ }^{13}$ also reported a positive correlation between the number of oocytes with a dispersed cumulus cell pattern at the time of denudation and an increasing time interval between human chorionic gonadotrophin and oocyte denudation, and Bokal et $\mathrm{al}^{4}$ found a significantly higher number of metaphase II oocytes in their human chorionic gonadotrophin +38 -hour group than in their human chorionic gonadotrophin +34 hours group in controlled ovarian hyperstimulation cycles, resulting in higher clinical pregnancy rates. This was attributed to the increased quantity of embryos available to select for transfer.

Bokal et $\mathrm{al}^{4}$ suggested that longer exposure to human chorionic gonadotrophin increased follicular vascularization and, thus, oocyte quality, due to a high concentration of vascular endothelial growth factor. However, in in vitro

Table I Clinical and demographic data

\begin{tabular}{|c|c|c|c|c|c|c|c|c|c|}
\hline & \multicolumn{3}{|c|}{ Group I } & \multicolumn{3}{|c|}{ Group 2} & \multicolumn{3}{|c|}{ Group 3} \\
\hline & Mean & SD & Sum & Mean & SD & Sum & Mean & SD & Sum \\
\hline Women's age (years) & 28.75 & 4.02 & & 28.78 & 3.85 & & 29.63 & 4.7 & \\
\hline Hours from injection (n) & 36.3 & 0.42 & & 38.23 & 0.31 & & 40.58 & 0.957 & \\
\hline Cumulus oopherus (n) & |3.|| & 5.05 & $|73|$ & 14.19 & 6.09 & 1022 & 14.46 & 6.5 & 1518 \\
\hline Mature oocytes (n) & 9.37 & 4.18 & 1237 & | I.7| & 5.52 & 843 & 12.72 & 5.96 & 1336 \\
\hline Oocytes injected (n) & 9.7 & 4.28 & $|28|$ & 11.85 & 5.56 & 853 & 13.04 & 6.16 & 1369 \\
\hline Oocytes fertilized (n) & 6.86 & 3.51 & 906 & 8.25 & 4.35 & 594 & 9.75 & 5.24 & 1024 \\
\hline Good embryos transferred (n) & 3.72 & 1.15 & & 3.43 & 1.38 & & 3.15 & 1.59 & \\
\hline
\end{tabular}

Abbreviation: SD, standard deviation. 
Table 2 Comparison between Groups I and 2

\begin{tabular}{|c|c|c|c|c|c|}
\hline & \multicolumn{2}{|l|}{ Group I } & \multicolumn{2}{|l|}{ Group 2} & \multirow[b]{2}{*}{$P$-value } \\
\hline & $\mathbf{n}$ & $\%$ & $\mathbf{n}$ & $\%$ & \\
\hline Maturation index & $1281 / 173 \mid$ & 74 & $853 / 1022$ & 83.46 & $0.00004^{*}$ \\
\hline Fertilization index & $906 / 1281$ & 70.7 & $594 / 853$ & 69.6 & 0.2948 \\
\hline \multirow[t]{2}{*}{ Positive clinical pregnancy index } & $27 / 132$ & 20.5 & $36 / 72$ & 50 & $0.000 *$ \\
\hline & Group I & & Group 3 & & \\
\hline Maturation index & $|28| /|73|$ & 74 & $1369 / 1518$ & 90.18 & $0.000 *$ \\
\hline Fertilization index & $906 / 1281$ & 70.7 & $1024 / 1369$ & 74.8 & 0.09 \\
\hline \multirow[t]{2}{*}{ Positive clinical pregnancy index } & $27 / 132$ & 20.5 & $64 / 105$ & 61 & $0.000 *$ \\
\hline & Group 2 & & Group 3 & & \\
\hline Maturation index & $853 / 1022$ & 83.46 & $1369 / 1518$ & 90.18 & $0.000 *$ \\
\hline Fertilization index & $594 / 853$ & 69.6 & $1024 / 1369$ & 74.8 & $0.039 *$ \\
\hline Positive clinical pregnancy index & $36 / 72$ & 50 & $64 / 105$ & 61 & 0.07 \\
\hline
\end{tabular}

maturation cycles, it is hard to confirm the effect of vascular endothelial growth factor because it is difficult to get follicular fluid from each follicle due to their small size. Another possibility could be that even though there is no direct evidence of the appearance of luteinizing hormone receptors in folliculogenesis, it is possible that some small follicles with an insufficient number of luteinizing hormone receptors might have responded following exposure for a longer time to human chorionic gonadotrophin (35 versus 38 hours), resulting in an increased number of oocytes with dispersed cumulus cells and a reduced number of oocytes with compacted or sparse cumulus cells. Interestingly, luteinizing hormone receptor expression has been confirmed in dispersed cumulus cells of oocytes generated from human chorionic gonadotrophin-primed in vitro maturation cycles. ${ }^{13}$ Therefore, we believe that prolonging the interval between human chorionic gonadotrophin administration and oocyte denudation would yield a higher number of oocytes with expanded cumulus cells, which predict higher maturation rates and developmental embryonic competence.

Previous studies done in patients with polycystic ovary syndrome indicate that there is no risk of ovulation when delaying oocyte collection after human chorionic gonadotrophin stimulation because the largest follicle size at the time of human chorionic gonadotrophin administration is $8-12 \mathrm{~mm} \cdot{ }^{4,12,13}$ However, our study was conducted in patients without polycystic ovary syndrome and with controlled ovarian hyperstimulation cycles, and we avoided the risk of oocyte ovulation by placing the cumulus oopherus collected at the time of ovum pickup into culture media, allowing further in vitro maturation.

Another explanation for the higher pregnancy rates observed in Group $3(P=0.000)$ and Group $2(P=0.000)$ in comparison with Group 1 could be the delay of denudation and injection time interval for oocytes, allowing time for meiotic spindle appearance, which is in agreement with a report by Kilani et a $1{ }^{14}$ who found that meiotic spindle appearance is time-dependent, with the majority of oocytes having detectable spindles and highest retardance at 39.0-40.5 hours after human chorionic gonadotrophin administration under currently used stimulation protocols, after which they start to disaggregate. The optimal time for intracytoplasmic sperm injection may be 39-40.5 hours following human chorionic gonadotrophin, and the time of oocyte injection in our study was $40.58 \pm 0.95$ hours in Group 3, $38.23 \pm 0.31$ hours in Group 2, and $36.3 \pm 0.42$ hours in Group 1 .

We agree with Weon-Young et al, ${ }^{13}$ that although numerous studies of in vitro maturation of immature human oocytes have been performed, compared with controlled ovarian hyperstimulation cycles, the efficiency of current in vitro maturation techniques is still suboptimal in terms of the number of mature oocytes obtained, developmental embryonic competence, and implantation rates.

We believe that further studies in a larger number of cases may clarify the optimal in vitro fertilization technique, and we are presently investigating the effects of addition of follicle-stimulating hormone and/or luteinizing hormone to the culture media, and whether the currently observed higher pregnancy rates are related to a delay in oocyte denudation and/or a delay in oocyte injection.

\section{Disclosure}

The author reports no conflicts of interest in this work.

\section{References}

1. Chian RC, Chung JT, Downey BR, Tan SL. Maturational and developmental competence of immature oocytes retrieved from bovine ovaries at different phases of folliculogenesis. Reprod Biomed Online. 2002;4:127-32. 
2. Kimura N, Hoshino Y, Totsukawa K, Sato E. Cellular and molecular events during oocyte maturation in mammals: Molecules of cumulus-oocyte complex matrix and signalling pathways regulating meiotic progression. Soc Reprod Fertil Suppl. 2007;63:327-42.

3. McElroy SL, Byrne JA, Chavez SL. Parthenogenic blastocysts derived from cumulus-free in vitro matured human oocytes. PLoS One. 2010;5:e10979.

4. Bokal EV, Vrtovec HM, Virant Klun I, Verdenik I. Prolonged HCG action affects angiogenic substances and improves follicular maturation, oocyte quality and fertilization competence in patients with polycystic ovarian syndrome. Hum Reprod. 2005;20:1562-8.

5. Raziel A, Schachter M, Strassburger D, Kasterstein E, Ron-El R, Friedler S. In vivo maturation of oocytes by extending the interval between human chorionic gonadotropin administration and oocyte retrieval. Fertil Steril. 2006;86:583-7.

6. Marchal R, Caillaud M, Martoriati A, Gerard N, Mermillod P, Goudet G. Effect of growth hormone $(\mathrm{GH})$ on in vitro nuclear and cytoplasmic oocyte maturation, cumulus expansion, hyaluronan synthases and connexins expression, and $\mathrm{GH}$ receptor mRNA expression in equine and porcine species. Biol Reprod. 2003;69:1013-22.

7. Dell'Aquila ME, Caillaud M, Maritato F. Cumulus expansion, nuclear maturation and connexin 43, cyclooxygenase-2 and FSH receptor mRNA expression in equine cumulus-oocyte complexes cultured in vitro in the presence of FSH and precursors for hyaluronic acid synthesis. Reprod Biol Endocrinol. 2004;2:44.
8. Vanhoutte L, Nogueira D, De Sutter P. During conventional in vitro maturation (IVM), oocytes undergo nuclear maturation but do not attain full cytoplasmic maturity. Hum Reprod. 2009;24:658-69.

9. Gudmundsson J, Fleming R, Jamieson ME. Luteinization to oocyte retrieval delay in women in whom multiple follicular growth was induced as part of an in vitro fertilization/gamete intrafallopian transfer program. Fertil Steril. 1990;53:735-7.

10. Son WY, Chung JT, Chian RC. A 38 h interval between hCG priming and oocyte retrieval increases in vivo and in vitro oocyte maturation rate in programmed IVM cycles. Hum Reprod. 2008;23:2010-6.

11. Yang SH, Son WY, Yoon SH, Ko Y, Lim JH. Correlation between in vitro maturation and expression of $\mathrm{LH}$ receptor in cumulus cells of the oocytes collected from PCOS patients in HCG-primed IVM cycles. Hum Reprod. 2005;20:2097-2103.

12. Kilani S, Cooke S, Chapman M. Time course of meiotic spindle development in MII oocytes. Zygote. 2010;23:1-8.
International Journal of Women's Health

\section{Publish your work in this journal}

The International Journal of Women's Health is an international, peerreviewed open-access journal publishing original research, reports, reviews and commentaries on all aspects of women's healthcare including gynecology, obstetrics, and breast cancer. Subject areas include: Chronic conditions (migraine headaches, arthritis, osteoporosis);

\section{Dovepress}

Endocrine and autoimmune syndromes; Sexual and reproductive health; Psychological and psychosocial conditions. The manuscript management system is completely online and includes a very quick and fair peer-review system. Visit http://www.dovepress.com/ testimonials.php to read real quotes from published authors.

Submit your manuscript here: http://www.dovepress.com/international-journal-of-womens-health-journal 